\title{
LA NOMENCLATURA DE ERNESTO JOSEPH EDER*
}

\author{
Manuel Alvar Ezquerra \\ Universidad Complutense de Madrid \\ malvar@filol.ucm.es
}

\section{Resumen}

Along this work I present a few known nomenclature, the Ernesto Joseph Eder "Vocabulario de los nombres y verbos más usados y necessarios" included in his bilingual grammar, Florilegio español y alemán y gramática de la lengua alemana para los españoles, y española para los alemanes [...], from 1714 .

The article study his relation with Juan Ángel de Zumarán's nomenclature and place the "Vocabulario" between the first steps on bilingual lexicography with German and Spanish.

Desde hace tiempo me atrae la atención un tipo especial de repertorios léxicos no alfabéticos, las nomenclaturas, a las que he dedicado algunos trabajos, de conjunto ${ }^{l}$ y de descripción de algunas de ellas ${ }^{2}$. Durante la recopilación de datos, y redacción, del Nuevo Tesoro Lexicográfico del Español (s. XIV-1726) (NTLE) hemos tenido en cuenta no pocas de ellas, pues su interés es evidente, aunque otras, por ser copia de obras anteriores, no han pasado a formar parte de él: carece de sentido repetir datos una y otra vez, máxime en el interior de un repertorio de las dimensiones del NTLE.

En las búsquedas para encontrar elencos de voces de nuestra lengua di con una nomenclatura de la que no tenía noticia, y de la cual no hablan los repertorios bibliográficos que manejo, lo cual no es de extrañar, pues, como muchas más, no es una obra independiente, sino que aparece en el interior de una gramática bilingüe, el Florilegio español y alemán o gramática de la lengua alemana para los españoles, y española para los alemanes [...] de

\footnotetext{
* Este trabajo se encuadra dentro de los llevados a cabo para el proyecto "Nuevo Tesoro Lexicográfico del Español (s. XIV-1726)" que goza de una ayuda del Ministerio de Ciencia y Tecnología (BFF2001-0263).

1 Por ejemplo, (1987): "Apuntes para la historia de las nomenclaturas del español". En Actas del VII Congreso Internacional de Lingüística y Filologia de América Latina (ALFAL). Homenaje a Pedro Henriquez Ureña. Santo Domingo, República Dominicana, 1984, t. I, Universidad Nacional Pedro Henriquez Ureña, Santo Domingo, págs. 457-470; recogido en Lexicografia descriptiva, págs. 277-287.

2 Como (1997): "Los repertorios léxicos de Alejandro de Luna". En Thesaurus. Boletín del Instituto Caro y Cuervo, LII, Homenaje a Rafael Torres Quintero, edición dirigida por Jaime Bernal Leongómez, págs. 45-51, recogido en (2002): De antiguos y nuevos diccionarios del español, Arco-Libros y Agencia Española de Cooperación Internacional, Madrid, págs. 232-238; y (1997): "La Nomenclatura de Lorenzo de Robles". En Manuel Almeida y Josefina Dorta (editores): Contribuciones al estudio de la lingüística hispánica. Homenaje al profesor Ramón Trujillo, II, Barcelona, Montesinos, págs. 15-26, también en De antiguos y nuevos diccionarios del espa$\tilde{n} o l$, págs. 239-252.
} 
Ernesto Joseph Eder ${ }^{3}$. Bien es cierto que esta gramática tampoco es muy citada ${ }^{4}$, y sólo la encuentro en la recopilación del Conde de la Viñaza ${ }^{5}$, donde parece una incorporación de última hora, entre las "Adiciones" finales (ficha $\mathrm{n}^{\circ}$ 1714). Sólo conozco un ejemplar de este Florilegio, conservado en una biblioteca pública'.

La nomenclatura que ahora me ocupa aparece bajo el título de Vocabulario de los nombres y verbos más usados y necessarios, y figura entre las páginas 194 y 200 del Florilegio. En realidad, ese Vocabulario acoge dos elencos bien diferentes. El primero, que aparece a continuación del título, es una nomenclatura. El segundo, después de ésta, es una relación alfabética, español-alemán, sólo de verbos, bajo un título muy parecido al común para los dos repertorios, Vocabulario de algunos verbos más usados y necessarios, que ocupa las páginas 221-231 de la obra. Por otro lado, en el interior de la gramática, como sucedía en otras obras similares, aparecen diferentes listas de palabras, aunque sin pretensión lexicográfica, como las encabezadas por los títulos "De los adverbios de tiempo" (págs. 126-127), "Los adverbios que significan un lugar" (págs. 127-129), "Los adverbios que significan una quantidad" (págs. 129-130), "Los adverbios de qualidat" (pág. 130), "Los adverbios para preguntar" (págs. 130-131), "Los adverbios para dessear" (pág. 131), “Los adverbios para assemejar" (pág. 131), "Los adverbios para comparar" (pág. 132), "De los adverbios para hortar" (pág. 132), "De los adverbios para dudar" (págs. 132-133), "De los adverbios para congregar y affirmar" (pág. 133), "De las conjunctiones copulativas" (págs. 133-134), "De lasa preposiciones" (págs. 134-135), todas ellas con el alemán a la izquierda (frente a los elencos finales en que la lengua que figura en ese lugar es el español). Hay, además, algunas otras relaciones de palabras, como las que ejemplifican el artículo, la formación de los plurales según la letra con que termine la voz alemana, con las declinaciones, los adjetivos, los números, pronombres, etc., que no son sino listas de ejemplos al hilo de la exposición gramatical.

La obra de Eder se completa con una lista de "Proverbios españoles" (págs. 271-273), que es una mera enumeración de refranes y frases proverbiales, a la que sigue otra en alemán, "Teutsche Sprüch-Wörter" (págs. 273-275), en la que pueden encontrarse equivalentes de los españoles.

En estos momentos no tengo datos suficientes para saber cuáles son las fuentes de la obra de Eder, pero no podemos olvidar la labor, casi un siglo antes, de Juan Ángel de Zu-

\footnotetext{
3 El título completo que figura en la portada es Florilegio español y alemán o gramática de la lengua alemana para los españoles, y española para los alemanes, con la mayor parte de los verbos puestos por abecedario, $y$ diversos diálogos, con muchíssimos proverbios, compuesta por D. Ernesto Joseph Eder, maestro de lenguas, impreso en Viena, por Juan Jorge Schlegel, Impressor de la Universidad, año 1714. Del impresor sabemos, efectivamente, que trabajaba para la Universidad de Viena, ciudad a la que llegó en 1693 (moriria en 1716), y que había abierto una de las siete librerías que poseía ésta. Sus impresiones eran de una calidad reconocida. Véase Anton Durstmüller (1981): 500 Jahre Druck in Österreich, Hauptverband der graphischen Unternehmungen, Viena, págs. 122-124.

4 Cae fuera del periodo considerado por Antonio Ramajo Caño (1987): Las gramáticas de la lengua castellana desde Nebrija a Correas. Universidad de Salamanca, Salamanca, y también del de Louis Kukenheim (1974): Contributions à l'histoire de la grammaire italienne, espagnole et française à l'époque de la renaissance. H\&S, Utrecht.

5 Biblioteca Histórica de la Filologia Castellana, 3 t., Imprenta y Fundición de Manuel Tello, Madrid, 1893; facsímil, Atlas, Madrid, 1978.
}

6 Biblioteca Histórica Municipal, Madrid, PAR-210. 
marán, quien en 1634 había publicado una gramática bilingüe ${ }^{7}$ con las mismas dos lenguas, completada con una nomenclatura también en esas lenguas. Esta obra no es sino la edición bilingüe de otra purilingüe anterior publicada en $1621^{8}$, algunas de cuyas partes, entre ellas la nomenclatura, repetirá el autor en otra obra de $1626^{\circ}$. La gramática de Zumarán es mucho más extensa que la de Eder, pero la nomenclatura de éste presenta concomitancias con la de aquél, al menos con la impresa en 1634. Bien es cierto que la estructura de ambas no es muy novedosa, y recuerda la de las derivadas de la que compuso César Oudin ${ }^{10}$, con algunos capítulos, como el de las partes del cuerpo, que entroncan con una larga tradición que echa sus raíces en la Edad Media.

A primera vista, la nomenclatura de Eder es una copia de la de Juan Ángel de Zumarán, pues, prácticamente, los capítulos en que se divide el léxico son los mismos. Tiene, no obstante, la de Eder un capítulo inicial de la que carece la otra, si bien no resulta nada nuevo dentro de la tradición de estas obras, que, con frecuencia, se abren un un epígrafe dedicado a Dios y las dignidades celestiales. Sin embargo, si examinamos su contenido, veremos que tiene muy pocas cosas en común con esos otros repertorios. Baste con leer el título del epígrafe, "De Dios, y de los elementos", para darnos cuenta de que su contenido no está exclusivamente relacionado con la religión, lo cual se confirma en su interior. El resto de los capítulos sigue en ambas obras el mismo orden, con ligeros cambios en algunos títulos, y pocas diferencias más: los capítulos 10 y 11 de Zumarán, "De los edificios ecclesiásticos y escolásticos, con sus partes" y "Edificios políticos y militares con sus pertenencias y propriedades", constituyen en la nomenclatura de Eder parte de su capítulo 9, "De los edificios y sus partes", aunque están diferenciados en su interior.

Faltan en la nomenclatura de nuestro Florilegio algunos grupos que aparecen en la de la Grammática y pronvnciación. A saber, no contiene el capítulo 27 de ésta, "Para aprender a contar", con sus subapartados "Números ordinales", "Aduerbialmente", "Para multiplicar", "De vna otra suerte", "Aduerbialmente de vna otra suerte", "Para diuidir" y "De dignidad", probablemente porque parte del léxico contenido en ésta ya constara en las listas de la primera parte de la gramática. También prescindió de otras series de palabras que constan en el interior del capítulo 29, "Del tiempo, edad, fiestas del año y días de la semana, con sus lugares, nonbres y circunstancias", para dejar tan sólo "De los [sic] más principales fiestas del año" (capítulo 26); los epígrafes suprimidos son "No[m]bre de los días de la semana", "Nombre de los meses", donde hay más léxico del que se pueda esperar por los encabezamientos. Igualmente, no ha pasado de Zumarán a Eder el capítulo 30, "De las monedas y sus partes".

7 Grammática y pronvnciación alemana y española, española y alemana, compuesta en beneficio de estas dos naciones, que quieren aprender vna destas lenguas, Viena, Miguel Riccio, 1634; de ella hay una reproducción facsimilar moderna, con comentario, hecha por Dieter Messner (2000): en Los manuales de español impresos en Viena en el siglo XVII. Institut für Romanistik der Universität Salzburg, Salzburgo.

8 Das newe Sprachbuch [...] Libro muy prouechoso para aprender las lenguas, Viuda de Vergianam, Munich, 1621 .

9 Thesaurvs findamentalis, quinque lingvarvm hoc est liber ex quo veluti clivitecornv copiae rectissima eaque facillima methodo [...], Wilhelm Eder, Ingolstadt, 1626.

10 El Nomenclator que hay en sus Diálogos en Español y Françés. Dialogues en François \& Espagnol. Avec des Annotations és lieux necessaires pour l'explication de quelques difficultez Espagnolles. Avec un Nomenclator de quelques particularitez qui se presentent à tout propos, François Foppens, Bruselas, 1604. 
Por lo demás, la distribución de los epígrafes, repito, es la misma, incluso cuando Zumarán ofrece como subapartados del capitulo octavo, "De los officios y dignidades temporales", los titulados "Officios de corte" y "Officios de guerra", que se repiten sin cambios en el otro. También se repite el capítulo 20, apéndice del que le precede, sin que Eder se tomara la molestia de incluirlo en él, aunque fuese como un epígrafe particular.

Las diferencias entre una y otra nomenclatura pueden observarse, igualmente, en el interior de los capítulos, pues aunque en la primera impresión el contenido pueda parecer idéntico, una mirada detenida nos muestra en seguida que las dos obras no son completamente iguales. Veamos un solo ejemplo. El primer capítulo común a las dos nomenclaturas es el que Zumarán encabeza como "De las junturas, miembros y partes del hombre", y Eder como "Del hombre y de sus miembros". El orden de las palabras es el mismo, aunque en el primero hay más palabras ${ }^{11}$ : cabellos crespados, las guedejas, la barua o baruilla, recobrar el aliento, aliento hediondo, el copete, lagrimal del ojo, blanco del ojo, etc. En no pocas ocasiones, en el texto de Eder faltan algunos de los sinónimos españoles que constan en el otro $^{2}$ : la garganta, el gañón; la cara, el jesto, rostro; niña, o niñilla del ojo; el mostacho, bigote; la espalda, el espinaço; el culo, rabo o trasero. En un caso se ha cambiado la forma de la palabra española: la baruilla de Zumarán es la baruita de Eder. Las diferencias se acrecientan hacia el final del epígrafe, pues hasta llegar a la planta del pie no hay nada en esta nomenclatura que no esté en la de 1634, pero a continuación figura el callo, y más adelante la verruga, el lado, la láchryma, los cinque sentidos, que no están en ésa, como tampoco están las últimas, desde el intentimiento hasta un feo. Las diferencias entre el capítulo 15 de Zumarán, "De los cauallos, carros y cosas tocantes a ellos", y 13 de Eder, con el mismo título, son evidentes, pues aquél es más extenso, aunque éste recoge alguna palabra que no consta en Zumarán. En otros capítulos, las diferencias resultan menores, por la misma naturaleza del texto, y así en el n ${ }^{\circ} 16$ de Eder, "De los nombres de los pescados", que se corresponde con el 18 de Zumarán, se repite éste, salvo una forma, el hueuo de pescado, dos sinónimos (lucio, brochete; ostias o óstreas), y reestructura lo que en Zumarán es una entrada triple (merluça, bacallao, abadejo) para hacer de ella dos (merluça y bacallao, perdiéndose abadejo).

Podría continuar esta comparación, pero no creo que merezca la pena. La conclusión resulta fácil: es posible que Eder tuviera delante la nomenclatura de Zumarán, a la que siguió con fidelidad, pero introduciendo cambios, a no ser que empleara otra obra en la que apareciesen ya esas modificaciones.

La nomenclatura de Eder no es una obra original, pero resulta interesante porque muestra cómo se efectúa la transmisión de los repertorios no alfabéticos de dos lenguas que no andaban muy sobradas de ellos. Baste con recordar que la lexicografía bilingüe alfabética con el español y el alemán tenía muy pocos años de existencia cuando ve la luz el Florilegio de Eder. El Diccionario muy copioso de la lengva española, y alemana ${ }^{13}$, de Nicolás Mez de

\footnotetext{
11 Tomo nada más que las formas españolas.

12 Subrayo las formas que no aparecen en Eder.

13 El título completo es Diccionario muy copioso de la lengva Española, y Alemana hasta agora nunca visto, sacado De diferentes Autores con mucho trabajo, y diligencia por Nicolas Mez de Braidenbach, Maestro en Artes, y Notario, Viena, Juan Diego Kürner, 1670; recientemente ha sido publicado en facsímil por Dieter Messner (1999): juntamente con su Gramática, o Instrucción española y alemana (1666), Institut für Romanistik der Universität Salzburg, Salzburgo, con un estudio preliminar.
} 
Braidenbach, alfabético, se había publicado en 1670 , y la nomenclatura que se anuncia en el título de su Gramática ${ }^{i 4}$ no es merecedora de ese nombre, pues lo que contiene al final son unas breves listas de palabras distribuidas por categorías gramaticales (los adverbios y los verbos ordenados desde el alemán), algunas de las cuales persiguen objetivos no estrictamente léxicos (por ejemplo, los verbos que presentan diptongaciones en su conjugación), por lo que la nomenclatura de Eder poco tiene que ver con la otra, como tampoco parece la lista de verbos de Mez de Braidenbach fuente de la de Eder, si bien no podemos negar de manera tajante que le diese la idea para componer la suya, aunque la de éste ordene los verbos a partir de la forma española.

Que la obra de Eder no es totalmente suya lo dice claramente en la nota inicial "Al lector" cuando escribe: "Querido lector, aquí os doy un nuevo y provechoso Florilegio, en el qual hallaréys muchas, y lindas flores, sacadas de diferentes jardines para beneficio vuestro, y que podáys con menos trabajo de sus odoríficas virtudes, y sacar grande utilidad".

Pese a su escaso interés, transcribo a continuación la nomenclatura de Eder, con la lista de verbos que la completa, por la rareza de las dos listas de voces, y para que el lector tenga en sus manos un elemento más para conocer los primeros pasos de la lexicografía bilingüe con el español y el alemán, en los que Viena desempeñó un papel fundamental como centro de impresión y difusión de obras.

\section{VOCABULARIO}

de los nombres y verbos más usados y necessarios

Das Vocabularium aller nothwendigen und mehr gebrauchlichen Wörtern und Verborum

De Dios, y de los elementos

Von Gott und von denen Elementen

$\begin{array}{llll}\text { Dios } & \text { Gott } & \text { el trueno } & \text { der Donner. } \\ \text { Dios Padre } & \text { Gott der Vatter } & \text { el relámpago } & \text { der Bliz. } \\ \text { Dios Hyo } & \text { Gott der Sohn } & \text { el hogar } & \text { der Herd. } \\ \text { Dios Espiritu Santo } & \text { Gott der H. Geist } & \text { el horno } & \text { der Ofen. } \\ \text { La Divinidad } & \text { Die Gottheit } & \text { la lámpara } & \text { die Ampel. } \\ \text { La Trinidad } & \text { Die Dreysalitgseit } & \text { la linterna } & \text { die Latern. } \\ \text { un ángel } & \text { ein Engel. } & \text { la vela de çera } & \text { die Waxkerzen. } \\ \text { un arc-ángel } & \text { ein Erzengel. } & \text { la vela de sevo } & \text { die Inssletkerzen. } \\ \text { el diablo } & \text { der Teuffel. } & \text { el acha } & \text { die Fackel, die Windliecht. } \\ \text { el alma } & \text { die Seel. } & \text { el tizón } & \text { das Brandscheid. } \\ \text { el paradiso } & \text { das Paradeiss. } & \text { el brazero [brasero] } & \text { die Gluipfanne. } \\ \text { el purgatorio } & \text { das Fegfeuer. } & \text { el incensario } & \text { das Rauchfass. } \\ \text { el fuego } & \text { das Feuer. } & \text { el llama } & \text { die Flamme. } \\ \text { el aire } & \text { der Luft. } & \text { la ceniza } & \text { der Aschen. } \\ \text { el viento } & \text { der Wind. } & \text { el humo } & \text { der Rauch. } \\ \text { el agua } & \text { das Wasser: } & \text { el aparemento[aparamento] } & \\ \text { la tierra } & \text { die Erden. } & \text { de encender fuego } & \text { der Feuerzeug. }\end{array}$

14 Gramática, o Instrucción española y alemana, compuesta cun método nuevo y muy fácil, con algunas sentencias, refranes, versos y exemplos para escribir cartas. También con Nomenclatura y algunos disticos del juego de la fortuna para los que quieran aprender alguna destas lenguas, Susana Rickesin, Viena, 1666. 
la iesca

la polvera

el azufre

la mecha

la leña

el carbón

el azeyte

el grasso de tozino

el sevo

la çera

la pez

la nieve der Zunder:

das Pulver.

der Schweffel.

der Lunten.

das Holz.

die Kohlen.

das Oel.

das Schmer:

das Insslet.

das Wax.

das Pech.

der Schne. el ielo

el granizo

el rocío

el miel

la laguna

el mar

el río

la fuente

el pozo

la cisterna

el baño das Eyss.

der Hagel.

der Reiff, der Than.

das Hönig.

der See.

das Meer:

der Fluss.

der Brumn.

der Schöpffbrunn.

die Cistern.

das Bad.

\section{$\S 2$. Del hombre y de sus miembros Von dem Menschen und seinen Glidern}

hombre
la gente
la persona
la estatura
la cabeça
los cabellos
un pelo
la calabera de la cabeça
el seso, celebro
el cogote, pescueço
el cuello
la garganta
la cara
el car[rilio
la lengua
el paladar
el diente
las muelas
el aliento
la frente
la ceja
el ojo
la buelta del ojo
niña del ojo
las pestañas
la nariz
las narizes
el moco
mocoso
la boca
la barvita
los labios
el mostacho
a

der Mensch.

das Volck.

die Persohn.

die Statur, oder Gestalt.

der Kopf, oder Haubt.

die Haar.

ein Haar.

die Hirnschal.

das Gehim.

das Genïck.

der Halss.

die Gurgel.

das Angesicht.

das Wang.

die Zung.

der Gaum.

der Zahn.

die Stockzähne.

der Athem.

die Stirn.

das Augenbraun.

das Aug.

der Augenblick.

der Augapfel.

die Haar an Augenglidern.

die Nasse.

die Nassenlöcher.

der Roz.

rotziger.

der Mund.

das Kinback.

die Leffzen.

der Knebelbart. raer la barba

la espalda

el braço

el codo

la mano

el palmo

el puño

el dedo

el pulgar

las uñas

la mano derecha

la mano izquierda

el cuerpo

los ñudos de los dedos

la juntura

la oreja

el espinaco [espinaço]

la costilla

el coracón [coraçón]

el pecho

el estómago

el liviano, polmón

el baco [baço]

las tripas, o entrañas

los riñones

el hígado

la teta

el ombligo

la barriga 0 vientre

la orina

el orinal

la parida

la saliva bartscheren.

die Schulter oder Achsel.

der Armb.

der Ellenbogen.

die Hand.

die Span.

der Faust.

der Finger.

der Daum.

die Näglen.

die rechte Hand.

die lincke Hand.

der Leib.

die Knochen, oder Finger.

das Glid.

das Ohr.

der Ruckengrad.

die Ripp.

das Herz.

die Brust.

der Magen.

die Lumpel.

das Milz.

die Därm.

die Nirn.

die Leber.

das Wärzlan der Brust.

der Nabl.

der Bauch.

der Harm.

das Harmglass.

die Kinderbetherin.

der Speichel. 


\begin{tabular}{|c|c|c|c|}
\hline el muslo & die Hifft. & la madriz & die Gebährmuiter. \\
\hline las nalgas & die Arschbacken. & el macho & das Männlein. \\
\hline el culo o trasero & der Arsch, Hintern. & la hembra & das Weiblein. \\
\hline un pedo & ein Furz. & el tuétano, meollo & das March. \\
\hline la rodilla & das Knie. & el miembro & das Glid. \\
\hline la piema & die Schenckl. & la verruga & die Wärz. \\
\hline la pandorilla [pantorrilla] & der Wadel. & el lado & die Seiten. \\
\hline el pie & der Fuss. & la láchryma & der Zäher. \\
\hline los dedos del pie & die Zähen. & los cinque sentidos & die fünff Sinnen. \\
\hline la planta del pie & die Fusssohlen. & la vista & das Gesicht. \\
\hline el callo & das Hïnerang. & el olor & der Gernch. \\
\hline el sudor & der Schweiss. & el oýdo & das Gehör. \\
\hline el huesso & das Bein. & el gusto & der Geschmack. \\
\hline los huessos & das Gebein. & el tacto & der Griff. \\
\hline el pellejo & die Hant. & la memoria & die Gedächtmuss. \\
\hline la came & das Fleisch. & el intentimiento [entendimiento] & der Verstand. \\
\hline la sangre & das Blut. & la voluntad & der Wissen. \\
\hline las arterias & die Flachs oder Lufftadern. & un enano & Ein Zwerg. \\
\hline la vena & die Ader. & un giboso & ein Bucklichter. \\
\hline el sueño & der Schlaff. & un sordo & ein Gehörloser. \\
\hline el sueño & der Traum. & un ciego & ein Blinder. \\
\hline la grassa o gordura & die Feiste. & un tuerto & ein Einaugiger. \\
\hline flaco & mager. & un mudo & ein Stummer. \\
\hline gordo & fett. & un $f_{0}$ & ein Schändlicher. \\
\hline
\end{tabular}

\section{De las virtudes de los hombres Von den Tugenden dess Menschen}

un hombre de bien
verdadero
discreto
prudente
ingenioso
sabio
de buena fama
docto
letrado
fiel, leal
animoso
valiente
fuerte
exemplar

$\begin{array}{ll}\text { ein ehrlicher Mann. } & \text { devoto } \\ \text { wahrhaffter. } & \text { casto } \\ \text { bescheidener. } & \text { obediente } \\ \text { fürsichtiger. } & \text { pacífico } \\ \text { sinnreicher. } & \text { alegre } \\ \text { weiser. } & \text { robusto } \\ \text { von guten Ruthm. } & \text { galán } \\ \text { gelehrter. } & \text { bravo } \\ \text { geschickter. } & \text { mujer honrada } \\ \text { getrener. } & \text { virtuosa } \\ \text { beherzter. } & \text { honesta } \\ \text { dapfferer. } & \text { casta } \\ \text { starcker. } & \text { piadosa }\end{array}$

andächtiger. keuscher. gehorsamer. fridsamer. frölich. mannhaffiger. politsauber. wackerhuitg. ehrliche Frau. tugendsam. ziichtige. keusche. fromme.

exemplarischer.

$\S 3$. De los vicios del hombre Von denen Untugenden dess Menschen

hombre de mala fama mentiroso malicioso ein Mensch eines bösen Nahmens. lingenhafft. bosshafft. astuto, arguto

astucia

adulador, lisonjero listig, arg.

Arglistigteit.

Schmeichler. 


$\begin{array}{llll}\text { alagos o lisonjas } & \text { Schmeichlerey. } & \text { salteador o matador } & \text { mörder oder todtschläger. } \\ \text { ambición } & \text { Ehrgeiss. } & \text { el alcahuete, rufián } & \text { der Rupler. } \\ \text { ambicioso } & \text { ehrgeissig. } & \text { el putañero } & \text { der hurentreiber. } \\ \text { adúltero } & \text { ehebrecher. } & \text { la ramera, puta } & \text { die Hur. } \\ \text { adúltera } & \text { ehebrecherin. } & \text { vellaco } & \text { unnussig. } \\ \text { avarizia } & \text { Geiss. } & \text { ocio } & \text { Müssigang. } \\ \text { atrevimiento } & \text { Frechheit. } & \text { deslealdad } & \text { Meyneiydigkeit. } \\ \text { bevedor } & \text { ein Sauffer. } & \text { obstinación } & \text { Halstärigkeit. } \\ \text { goloso } & \text { gefrässig. } & \text { el traydor } & \text { der Verräter. } \\ \text { boracheria [borrachera] } & \text { vollsaufferey. } & \text { la amotinación } & \text { die Auffruhr. } \\ \text { entonado, altivo } & \text { auffgeblasen, stolz. } & \text { loco, tondo [tonto], o bovo } & \text { ein Narr. } \\ \text { espión } & \text { ein Kundschaffier. } & \text { supersticioso } & \text { Aberglaubig. } \\ \text { ladrón } & \text { Dieb. } & \text { tyrano, cruel } & \text { Tyranisch. } \\ \text { engañador } & \text { betrïger. } & \text { un hachizero [hechizero], } & \\ \text { desconocido } & \text { undanckbar. } & \text { encantador } & \text { ein Hexenmeister. } \\ \text { enemistad } & \text { feindschaffi. } & \text { una bruxa } & \text { ein Hex. } \\ \text { insensato } & \text { unsinnig. } & \text { el vicio } & \text { das Luster. } \\ \text { arrabiado } & \text { zornig. } & \text { la usura, usurero } & \text { der Wucher, wicherer. } \\ \text { cólera } 0 \text { ira } & \text { der Zorn. } & \text { la picardia } & \text { die Bettlerey. } \\ \text { enbidia } & \text { Missgunst, Neyd. } & \text { la ypócrita } & \text { die Gleissnerey. } \\ \text { liviandad } & \text { Leichtfertigkeit. } & \text { el lisonjero } & \text { der Heuchler. }\end{array}$

\section{$\S 4$. De los vestidos y sus especies Von den Kleydungen und ihrer Zugehöre}

$\begin{array}{ll}\text { el sombrero } & \text { der Hut. } \\ \text { la camisa } & \text { das Hemmet. } \\ \text { la escofia o bir[r]ete } & \text { die Nachthauben. } \\ \text { el pañizuelo } & \text { das Fazenet. } \\ \text { los puños } & \text { die Täzel. } \\ \text { calconillos [calçonillos] blancos } & \text { die Schlaffhossen. } \\ \text { escarpines de tela, } & \text { die Fusssäckel. } \\ \text { el almilla } & \text { das wolleng Hemetl. } \\ \text { el botón } & \text { der Knopff. } \\ \text { el ojal } & \text { das Knopffloch. } \\ \text { calçones } & \text { die Hossen. } \\ \text { calçetas o medias } & \text { die Strimpf. } \\ \text { atapiernas } & \text { die Kniebändl. } \\ \text { el çapato } & \text { die Schuch. } \\ \text { la suela } & \text { die Solen. } \\ \text { chinelas o pantoflas } & \text { die Pantofl. } \\ \text { botas } & \text { die Stiffel. } \\ \text { espuelas } & \text { die Sporn. } \\ \text { sobremedias } & \text { Reutstrimpff. } \\ \text { la capa } & \text { der Mantl. } \\ \text { un coleto } & \text { ein Goller. } \\ \text { la toquilla de sombrero } & \text { die Hutschnur. } \\ \text { el bradicu } & \text { das Wöhrgehäng. } \\ & \\ & \end{array}$

$\begin{array}{ll}\text { una ropa de muger } & \text { ein Weiberrock. } \\ \text { una saya } & \text { ein Rock. } \\ \text { la orilla del vestido } & \text { der Saum an Kleyd. } \\ \text { vestido } & \text { ein Kleyd. } \\ \text { vestido del luto } & \text { ein Klagkleyd. } \\ \text { un pliego [pliegue] o rupa [ruga] } & \text { ein Falten. } \\ \text { un devantal } & \text { ein Fürtuch. } \\ \text { un pellejo, matafrío } & \text { ein Belz. } \\ \text { una bata o cota de chambre } & \text { Schlafrock. } \\ \text { un alfiler } & \text { ein Spennadl. } \\ \text { una sortija } & \text { ein Ring. } \\ \text { una petrina o cíngulo } & \text { ein Gürtl. } \\ \text { carcillos [carcillos] o arracadas } & \text { Ohrgehäng. } \\ \text { puntas, randas } & \text { Spitzen. } \\ \text { hevilla de zapatos } & \text { Schuchschnal. } \\ \text { faltriguera [faltriquera] } & \text { Schub-Sack. } \\ \text { una manga } & \text { ein Ermbl. } \\ \text { bolsa } & \text { ein Beutl. } \\ \text { un collar d'oro } & \text { ein golden Kehlband. } \\ \text { una cadena d'oro } & \text { ein goldene Ketten. } \\ \text { joyas } & \text { Kleynodien. } \\ \text { un manguito } & \text { ein Stuzen. } \\ \text { un guante } & \text { ein Handschuch. } \\ & \\ \text { an } & \end{array}$




\section{$\S 5$. De las materias con las quales se hazen los vestidos Von den Zeug mit welchen man die Kleyder macht}

$\begin{array}{llll}\text { terciopelo } & \text { Gamet. } & \text { tripa de terciopelo } & \text { Tribsamet. } \\ \text { raso } & \text { Atlas. } & \text { seda } & \text { Seiden. } \\ \text { damasco } & \text { Damasc. } & \text { galones } & \text { Borten. } \\ \text { taffetán } & \text { Taffet. } & \text { fustán } & \text { Barchet. } \\ \text { brocado o tela de oro } & \text { goldenes Stuck. } & \text { lana } & \text { Woll. } \\ \text { tela de plata } & \text { silbernes Stuck. } & \text { tela } & \text { Leinwath. } \\ \text { bordado } & \text { Gestickt. } & \text { cordován } & \text { Cordevan. } \\ \text { bordadura } & \text { Stickeren. } & \text { hilo } & \text { Zwirn, Faden. } \\ \text { paño de Espana } & \text { spanisch Tuch. } & \text { aguja } & \text { Nadel. } \\ \text { paño de Inglaterra } & \text { englisch Tuch. } & \text { dedal } & \text { Fingerhut. } \\ \text { paño de Francia } & \text { französisch Tuch. } & \text { cuero } & \text { Leder. } \\ \text { chamelote } & \text { camelot. } & \text { camuça } & \text { Gämbshaut. } \\ \text { grana o escariata } & \text { Scharlach. } & \text { aforro } & \text { Fudertuch. } \\ \text { sendal } & \text { Zendel. } & \text { vayeta } & \text { Bay. } \\ \text { carmesí } & \text { Carmesin. } & \text { estopa } & \text { Werch. } \\ \text { algodón } & \text { Baumwoll. } & & \end{array}$

$\S 6$. De las cosas tocantes a una casa dentro y fuera Von den Sachen so in ein Hauss in- und ausswendig gehören

palacio real
corte de príncipe
un castillo
la casa
la casilla
la sala
la galería o corredor
el aposento
el aposento de estuffa
la estuffa, horno,
la chimenea
la botega [bodega] o cantina
la cozina
privada o necessaria,
el saguán [zaguán] o patio
el establo
pesebre
el tejado
la ventana
la puerta
la puertecilla
la escalera
cala ma
el armadura de cama
la cortina

$\begin{array}{ll}\text { käniglicher Pallast. } & \text { el calçador } \\ \text { fürstlicher Hoff. } & \text { a sáanana } \\ \text { ein Schloss. } & \text { el almohada } \\ \text { das Hauss. } & \text { la cubierta o manta, } \\ \text { das Häussl. } & \text { la paja } \\ \text { der Saal. } & \text { el pajar } \\ \text { der Gang. } & \text { el colchón } \\ \text { das Zimmer. } & \text { el fuente } \\ \text { die Stuben. } & \text { el jarro o jarra } \\ \text { der Ofen. } & \text { la servilleta } \\ \text { der Kamin. } & \text { la toalla de mesa } \\ \text { der Keller. } & \text { el plato } \\ \text { die Kuchel. } & \text { la mesa o tabla } \\ \text { heimlich gemach. } & \text { la silla } \\ \text { der Hoff in Hauss. } & \text { el taburete } \\ \text { der Stall. } & \text { el banco } \\ \text { Varm oder Krippe. } & \text { el salero } \\ \text { das Dach. } & \text { la chuchara [cuchara] } \\ \text { das Fenster. } & \text { el tenedor } \\ \text { das Thor. } & \text { la taça o copa } \\ \text { das Thürl. } & \text { la taça de vidrio } \\ \text { die Stiegen. } & \text { el assador } \\ \text { das Beth. } & \text { las parrillas } \\ \text { die Bethstat. } & \text { la pala } \\ \text { der Fürhang. } & \text { los fuelles }\end{array}$

der Anzieher. das Leilach. das Kïss. die Decken. das Stroh. der Strohsack. der Matrassen. das Handbeck. das Giesskand. das Tischsalvet. das Tischtuch. das Deller, oder die Schissl. der Tisch. der Sessel. der Stul. die Banck. das Salzfass. der Löffel. die Gabel. der Becher. das Glass. der Bratspiess. der Rost. die Feuerschouffel. der Blasbalck. 


la botija o flasco
la aguja de enlardar
las tenazas
el candelero
el despavilador
el tonel o bota
la llave
el orinal
el servidor o bacín
un aparador
una caldera
el cofre o arca
la cesta

la botija o flasco

la aguja de enlardar

las tenazas

el candelero

el despavilador

el tonel 0 bota

la llave

el orinal

el servidor o bacín

un aparador

una caldera

la cesta

$\begin{array}{lll}\text { die Flasche. } & \text { el despertador } & \text { der Wecker. } \\ \text { die Spicknadel. } & \text { el clavo } & \text { der Nagel. } \\ \text { die Feuerzange. } & \text { la rueca para hilar } & \text { der Rock. } \\ \text { der Leuchter. } & \text { el huso } & \text { die Spindl. } \\ \text { die Liechtbuzen. } & \text { un cedaço } & \text { ein Sib. } \\ \text { das Vas. } & \text { la cuna } & \text { die Wiegen. } \\ \text { der Schlïssl. } & \text { el embudo } & \text { der Trachter. } \\ \text { das Nachtgeschirr. } & \text { sartén para calentar la cama } & \text { ein Bethpfarne. } \\ \text { der Leibstul. } & \text { un brasero } & \text { ein Glutpfan. } \\ \text { ein Anrichttisch. } & \text { el rallo } & \text { das Ribeysen. } \\ \text { ein grosser Kessel. } & \text { la escoba } & \text { der Bessen. } \\ \text { die Truchen, oder Kaysstruchen. } & \text { la escobilla } & \text { die Kehrbürsten. } \\ \text { der Korb. } & \text { el peine } & \text { der Kämpel. }\end{array}$

$\S 7$. De las dignidades y officios de los ecclesiásticos Von denen geistlichen Dignitäteb und Aembtern
el papa
el pontificado
el patriarca
el cardenal
el arçobispo
el obispo
el abad
el prepósito
la præpositura
el archi-preste
el archi diano
el general
el vicario general
el procurador general
el provincial
el prior
el priorato

$\begin{array}{ll}\text { der Pabst. } & \text { el suprior } \\ \text { das Pabsthum. } & \text { el retor } \\ \text { der Patriarch. } & \text { el canónigo } \\ \text { der Cardinal. } & \text { el decano } \\ \text { der Erabischoff. } & \text { el obispo de anillo } \\ \text { der Bischoff. } & \text { el cura } \\ \text { der Abbt. } & \text { la par[r]oquia o curado [curato], } \\ \text { der Probst. } & \text { el sacerdote } \\ \text { die Probsten. } & \text { el maestro de capilla } \\ \text { der Erzpriester. } & \text { el organista } \\ \text { der Erzdiacon. } & \text { el ermitaño } \\ \text { der General. } & \text { el cantor } \\ \text { der general Vicari. } & \text { el sacristán } \\ \text { der general Procurator. } & \text { la abadessa } \\ \text { der Provincial. } & \text { la priora } \\ \text { der Prior. } & \text { la monja } \\ \text { das Priorat. } & \text { lego }\end{array}$

der Subprior.

der Rector.

der Thumherr.

der Dechant.

der Weyhbischoff.

der Pfarrherr.

die Pfarr.

der Priester.

der Capelmeister.

der Organist.

der Einsidler.

der Singer.

der Messner.

die Abbtissin.

die Priorin.

die Numne.

ein Ley.

\section{$\S 8$. De los officios y dignitades temporales Von denen weltlichen Aemptern und Dignitäten}

$\begin{array}{llll}\text { emperador } & \text { Käyser. } & \text { barón } & \text { Freyherr. } \\ \text { rey } & \text { König. } & \text { gentilhombre } & \text { Edelman. } \\ \text { archi-duque } & \text { Erzherzog. } & \text { hidalgo } & \text { Einer oder Adliger. } \\ \text { elector } & \text { elector imperial, Churfürst. } & & \\ \text { duque } & \text { Herzog. } & \text { officos de corde } & \text { Hoff-Aembter } \\ \text { príncipe } & \text { Fürst. } & & \\ \text { marqués } & \text { Marggraff. } & \text { mayor domo mayor } & \text { obrist Hoffmeister. } \\ \text { conde } & \text { Graff. } & \text { caballerizo mayor } & \text { obrist Stallmeister. } \\ \text { vice-conde } & \text { Vice-Graff. } & \text { camerero mayor } & \text { obrist Cammerer. }\end{array}$


presidente de estado mariscal de corte

catador mayor

presidente del Consejo

camerero

chanciller

consejero

governador

copero

trinchante

gentilhombre de la loca

gentilhombre de corde [corte]

cortesano

paje

secretario

ayudante de cámera

archero

alabardero

lacayo

escrivano

un furriel

un correo o postillón

Officios de guerra

vy rey

tiniente general

general de cavallería obrister Praesident.

Hoffmarschall.

obrist Jägermeister.

Cammer Praesident.

Cammerherr.

Canzler.

Rath.

Stadthalter.

Mundschenck.

Fürschneider.

Trucksäss.

Hoffjuncker.

Hoffmann.

Edelknab.

Secretari.

Cammerdiener.

Hartschir.

Trabant.

Laquey.

Schreiber.

Furrier.

Currier, oder Postillion.

Kriegs-Aembter:

Vicekönig.

General Leutenant.

General der Cavalleria. general de infantería

general de artillería

capitán de cavallos

capitán de infantería

tiniente

alferes [alférez]

cabo de esquadra o corporal

sargento

soldado

la sentinella [centinela]

el provoste

el vivandero

minador, gastador

una espía

un combate

un rumpimiento del exército

un hombre armado

un faraute

sitio de una ciudad

assalto

botín o despojo

batalla

guamición

artillero

un esquadrón

un trompeta

escaramuça

un tambor
General der Infanteria.

General Zeugmeister.

Rittmeister.

Hauptmann.

Leutenant.

Fenderich.

Corporal.

Wachtmeister.

Soldat.

Schildwacht.

der Prososs.

der Margatanter.

Minirer.

ein Spion.

ein Streit.

ein Niderlag.

ein Curisir.

ein Herold.

die Belägerung.

Sturm.

Raub, Beut.

Schlacht.

Befassung.

Schïtzenmeister.

ein Squadron.

ein Trompeter, Trompet.

Scharmizl.

ein Trommelschlager, Trommel.

\section{$\S 9$. De los edificios y sus partes \\ Von den Gebäuen und ihrer Zugehör}

fábrica, edificio
el fundamento
canales o goteras del tejado
cimiento, argamassa
coluna o pilar
suelo de tablas
ladrillo
el umbral de la puerta
ein Gebäu.
der Grund.
der Kinnen.
Mälter.
ein Saule.
taffleter Boden.
Ziegel.
Thïschwöll.

pared
muralla
empedrado
el portal
puntal o tranca de puerta
serradura [cerradura], contado
[candado]
bóveda

Wand.

Mauer.

Pflaster.

der Eingang.

ein Thürangel.

ein Schloss.

das Gewölb.

\section{De los edificios ecclesiásticos y escolásticos con sus partes Von denen Geistlichen und Schul-Gebäuen sambt ihrer Zugehör}

iglesia, templo
altàr
capilla

die Kirchen.

der Altar.

die Capelle. la pila bautismal

sacristía

un convento der Tauffstein. die Sacristey. das Closter. 


$\begin{array}{llll}\text { claustro } & \text { der Creuzgang. } & \text { escuela } & \text { Schul. } \\ \text { campanario } & \text { der Glockenthurn. } & \text { colegio } & \text { das Collegium. } \\ \text { coro } & \text { der Chor. } & \text { academia } & \text { die Academie. } \\ \text { el cimenterio } & \text { der Kirchhoff. } & \text { la universitad } & \text { die Universitäit. } \\ \text { el púlpito } & \text { der Predigstul. } & \text { la casilla adonde están los } & \\ \text { la sepultura } & \text { ein Grab. } & \text { huessos de los muertos, } & \text { Todtenhäusssl. } \\ \text { el auditorio } & \text { die Versammlung. } & & \end{array}$

De los edificios políticos y militares con sus pertenencias y propriedades Kriegs und politische Gebäu sambt ihrer Zugehör und Eigenschafften

casa de la ciudad, das Rathhauss.

la torre

la ciudad

la calle

el almazén

la fortaleza o castillo

rastrillo de puerta

la muralla el puente levadizo

plata forma

garita, atalaya

arrabales

prisión

la orca

el rollo

hospital die Fallbrucken. die Pastean.

ein Wachthäuss].

Vorstadt.

die Gesängmuss.

der Galgen.

der Pranger.

das Spitall.

$\S 10$. De los nombres de las armas, y cosas tocantes a la guerra Nahmen und Wäffen der Sachen so zu dem Krieg gehörig

armada puesta en batalla
la avanguardia
el cuerpo de batalla
la retroguardia
aparejo de guerra
la trinchera
una pieza de artillería
un mortero de guerra,
peto, coraça
espada
oja de espada
la bayna de la espada

$\begin{array}{ll}\text { ein Schlachtordnung. } & \text { alfange } \\ \text { der Vorzug. } & \text { el fusil } \\ \text { der Mittelzug. } & \text { la bayoneta } \\ \text { der Nachtzug. } & \text { la pólvora } \\ \text { Kriegsrïstung. } & \text { una carga } \\ \text { die Schanz. } & \text { la varilla } \\ \text { ein gross Geschïz. } & \text { la bala } \\ \text { ein Mörser. } & \text { tienda, pavillón } \\ \text { Brustharnisch. } & \text { una bandera } \\ \text { der Degen. } & \text { el estandarte } \\ \text { ein Klinge. } & \text { un corneta } \\ \text { die Schaid. } & \end{array}$

der Säbel.

die Flinten.

der Bavonet.

das Pulffer.

ein Ladung.

der Ladstecken.

die Kugel.

das Zeld.

der Fahn.

der Standart.

ein Cornet.

$\S 11$. De los libros, escrituras y nombres de las cosas a ellos tocantes Von denen Büchern, Schriften und Nahmen der Sachen so darzu gehören

$\begin{array}{llll}\text { papel } & \text { Papier. } & \text { memorial } & \text { ein Supplication. } \\ \text { una oja de papel } & \text { ein Bogen Papier. } & \text { un renglón } & \text { ein Zeil. } \\ \text { una mano de papel } & \text { ein Buch Papier. } & \text { una letra } & \text { ein Buchstab. } \\ \text { una rezma de papel } & \text { ein Kiz Papier. } & \text { cartas de favor } & \text { Recommendationbrieff. } \\ \text { pergamino } & \text { Pergament. } & \text { letras de cambio, } & \text { Wechselbrief. } \\ \text { el libro } & \text { das Buch. } & \text { una plana o página } & \text { ein Seiten dess Buchs. } \\ \text { un libro de escrivir } & \text { ein Schreibbuch. } & \text { una escrittura } & \text { ein Schriffi. } \\ \text { una cobertura del libro } & \text { ein eck dess Buchs. } & \text { un sello } & \text { ein Petschaft. } \\ \text { un librito } & \text { ein Büchl. } & \text { borradura } & \text { ein Radirung. }\end{array}$




inventario
un índice
título
quitança
un original
el traslado
pluma para escrivir

un cantor

baxón o bajista

altista

tenorista

un garganteador

una canción

la harpa

un laúd

un órgano

clavicordio

\author{
ein Inventarium. \\ ein Register. \\ ein Titl. \\ ein Quitung. \\ ein Original. \\ ein Copey. \\ Schreibfeder.
}

tinta

un tintero

arenera
Dinten.

ein Schreibzeug.

Sträh-Bix.

Federmesser.

ein Buchladen.

Fliesspapier.

ein Linier.

\section{$\S 12$. De los instrumentos y cosas músicas}

Von denen Instrumenten und was zu den Music gehört

$\begin{array}{lll}\text { ein Singer. } & \text { violón } & \text { Vassgeigen. } \\ \text { ein Bassist. } & \text { violin } & \text { Geigen. } \\ \text { Altist. } & \text { citara } & \text { ein Zitern. } \\ \text { Tenorist. } & \text { lyra } & \text { ein Leyren. } \\ \text { der Colaturenmacht. } & \text { la prima o tiple } & \text { Quintsaiten. } \\ \text { ein Gesang. } & \text { vihuela 0 quitarra [guitarra] } & \text { spanische Gittara. } \\ \text { die Härpffen. } & \text { las cuerdas } & \text { die Saiten. } \\ \text { ein Lauthen. } & \text { una flauta } & \text { ein Flauten. } \\ \text { ein Orgel. } & \text { címbalo } & \text { ein Zimbl. } \\ \text { ein Instrument. } & \text { atabales } & \text { Herpaucken. }\end{array}$

Von den Pfredten, Wagen und ihrer Zugehör

$\S 13$. De los cavallos, carros y cosas tocantes a ellos

un guarañón
una jumenta
cavallo de raça
cavallo capado
cavallo de escuela
cavallo de silla
cavallo de carga
cavallo de carro
potro
cavallito, haquilla
una mula
un asno
silla
brida, freno

ein Springhengst.
ein Stutte.
Gestutpferd.
Wollach oder geschnittenes Pferd.
Schulpferd.
Reitpferd.
Tragpferd.
Wagenspferd.
ein Fül.
ein Kleperl.
ein Maulthier.
ein Esel.
ein Satel.
ein Zaum.

los estribos
cavallerizo
picador
moço de cavallos
carrocero o cochero
carroça o coche
estrilla o almohaça
celemín de avena
pesebre
estércol
establo
cabestro
curriaga [çurriaga], azote
forrage, pasto

Stegraiff.

Stallmeister.

Bereiter.

Reitknecht.

Gutcher.

Wagen.

Strigl.

Mässthaber.

der Barm.

der Mist.

der Stall.

die Hulffter.

die Beutschen.

das Futter.
$\S 14$. De los animales quadrúpedes, assí domésticos como salvajes Von denen vierfüssigen Thieren, sowohl heimisch als wilde

$\begin{array}{llll}\text { un animal } & \text { ein Thier. } & \text { ternera, bezerra } & \text { lechter Kalb. } \\ \text { una vaca } & \text { ein Kuhe. } & \text { un torro [toro] } & \text { ein Stier. } \\ \text { bezerro o vitelo } & \text { ein Kalb. } & \text { un buey } & \text { ein Ochs. }\end{array}$




$\begin{array}{llll}\text { puerco } & \text { Schwein. } & \text { texón } & \text { Dachs. } \\ \text { una puerca } & \text { Sau oder Schwein. } & \text { mona } & \text { Aff. } \\ \text { el lechonzillo } & \text { Spensau. } & \text { búfalo } & \text { Biffel. } \\ \text { puerco javali } & \text { Wildschwein. } & \text { camello } & \text { Camel. } \\ \text { ciervo } & \text { Hirsch. } & \text { perro } & \text { Hund. } \\ \text { carnero } & \text { Widder. } & \text { perra } & \text { Hündin. } \\ \text { oveja } & \text { Schaff. } & \text { un galgo } & \text { Windspil. } \\ \text { cordero } & \text { Lamb. } & \text { cabrón } & \text { Bock. } \\ \text { liebre } & \text { Haass. } & \text { cabra } & \text { Geiss. } \\ \text { corra [çorra] } & \text { Fuchs. } & \text { cabrito } & \text { Kizel. } \\ \text { conejo } & \text { Königl. } & \text { gato } & \text { Kaz. } \\ \text { león } & \text { Löw. } & \text { ratón grande } & \text { Raz. } \\ \text { osso } & \text { Bär. } & \text { ratonçillo } & \text { Mauss. } \\ \text { lobo } & \text { Wolff. } & \text { unicornio } & \text { Einhorn. } \\ \text { cabra montés } & \text { Rech. } & \text { elefante } & \text { Elephant. }\end{array}$

\section{$\S 15$. De los nombres de páxaros o aves Von denen Vöglen}

$\begin{array}{ll}\text { páxaro } & \text { Vogel. } \\ \text { gavilán } & \text { Spercher. } \\ \text { calandria } & \text { Lerch. } \\ \text { falcón } & \text { Falck. } \\ \text { ánade } & \text { Aenten. } \\ \text { ganso, pato } & \text { Ganss. } \\ \text { águila } & \text { Adler. } \\ \text { capón } & \text { Capauner. } \\ \text { gallina } & \text { Henn. } \\ \text { gallo de India } & \text { indianischer Hann. } \\ \text { un gallo } & \text { ein Hann. } \\ \text { becada de agua } & \text { Schnepff. } \\ \text { paloma, pichón } & \text { Taube. } \\ \text { cuervo } & \text { Raab. } \\ \text { codorniz } & \text { Wachtel. } \\ \text { cizne [cisne] } & \text { Schwan. }\end{array}$

cuclillo Gugu.

grulla o gruga Krannich.

golondrina Schwalb.

ruyseñor Nachtigall.

mierla, mirla Ambsel.

palomas salvajes wild Tauben.

pavo Pfau.

gorrión, pardal Spaz.

perdiz

Rebhendl.

Fasan.

Alster.

urraca

papagayo

pollo

estomino, estornell

tórtora

tordo

Papagey.

Hendl.

Stärl.

Turteltauben.

Cranametsvogel.

\section{$\S 16$. De los nombres de los pescados Von denen Fischen}

un pescado
lucio
trucha
salmón
tortuga, galápago
óstreas
gámbaros
merluça
bacallao

$\begin{array}{ll}\text { ein Fisch. } & \text { carpa } \\ \text { Hechten. } & \text { lamprea } \\ \text { Forel. } & \text { anguila } \\ \text { Salm. } & \text { barbo } \\ \text { Schildtkrot. } & \text { harenque } \\ \text { Austern. } & \text { harenque seco o ahumado } \\ \text { Krebsen. } & \text { ballena } \\ \text { Laberdan. } & \text { escama } \\ \text { Stockfisch. } & \text { concha del pescado }\end{array}$

Kärpffen.

Bricke.

Aal.

Barben.

Höring.

Bückling.

Wallisch.

Schieppen.

Muschel. 
$\S 17$. De otras suertes de gusanos, moscas y bestias ponçonosas [ponçoñosas] Von ander Art und Geschlechtern de Würmen, Fliegen, und anderen vergifften Thieren

un gusano
un caracol
vípera
serpiente
un çapo
una rana
lagarto
araña
tela de araña
polilla
sanguijuela

ein Wurmb.
ein Schneck.
Nater.
Schlang.
ein Krott.
ein Frosch.
Ayderl.
ein Spinnen.
Spinnenweb.
Schaab.
Egel.

escorpion

grillo

escaravajo

zángano

chinche

ladilla

piojo

puelga [pulga]

liendre

mosca
Scorpion.

Grill.

Keffer.

Wepsen.

Wanzen.

Filzlauss.

Lauss.

Floch.

Niss in Haar.

Fliegen.

$\S 18$. Un apéndice del sobredicho capítulo, donde se declaran las partes y frutos de los animales

Ein Anhang von obgemelten Capitl, darinnen man die Theil und Fruchten der Thier erfläret

$\begin{array}{llll}\text { ala } & \text { Fligel. } & \text { tozino } & \text { Speck. } \\ \text { ámbar } & \text { Bisem. } & \text { la cola } & \text { der Schweif. } \\ \text { butiro } & \text { Butter. } & \text { miel } & \text { das Hönig. } \\ \text { manteca } & \text { Schmalz. } & \text { un huevo } & \text { ein Ay. } \\ \text { cera } & \text { Wax. } & \text { la clara } & \text { das Eyrklar. } \\ \text { un cuerno } & \text { ein Horn. } & \text { la yema del huevo } & \text { der Todter. } \\ \text { marfil } & \text { Helffenbein. } & \text { cáscaras de huevo, } & \text { Ayrchöller. } \\ \text { leche } & \text { Milch. } & \text { pluma } & \text { Feder. } \\ \text { flor de leche } & \text { Milchraim. } & \text { sevo } & \text { Insslet. } \\ \text { lana } & \text { Wohle. } & \text { almisque } & \text { Zuamet. } \\ \text { un jamón } & \text { ein Schuncken. } & & \end{array}$

$\S 19$. De todo lo que pertenece al casamiento Von allen Nothwendigkeiten zur Heyrath

$\begin{array}{llll}\text { bodas } & \text { Hochzeit. } & \text { una querida } & \text { ein Liebhaberin. } \\ \text { esposo } & \text { Bräutigam. } & \text { tutor } & \text { Vormunder. } \\ \text { novio } & \text { Hochzeiter. } & \text { curador } & \text { Pfleg-Vatter. } \\ \text { esposa } & \text { Braut. } & \text { padrino de las bodas } & \text { Brautfihrer. } \\ \text { novia } & \text { Hochzeiterin. } & \text { competidor de amor } & \text { Mitbuhler. } \\ \text { la dote de muger } & \text { Heyrat Gut. } & \text { enamorado } & \text { ein Liebhaber. } \\ \text { recién casado } & \text { junger Ehemann. } & \text { nuera } & \text { Schmir. } \\ \text { viudo } & \text { Wittwer. } & \text { cuñado } & \text { Schwager. } \\ \text { viuda } & \text { Wittib. } & \text { cuñada } & \text { Schwägerin. } \\ \text { suegro } & \text { Schweger. } & \text { compadre } & \text { Gevatter. } \\ \text { suegra } & \text { Schwiger. } & \text { comadre } & \text { Gevätterin. } \\ \text { yerno } & \text { Tochtermann. } & \text { partera } & \text { Heham. }\end{array}$


ama

hyo [hijo]

hyo [hijo] adoptado

hya [hija]

casamiento

patrimo [padrino] ama que cría, Seigam.

Sohn.

Angenommener Sohn.

Tochter.

Ehe.

vätterlich Gut. herencia

patria, tierra

marido

muger

generación
Erbschaffit.

Vatterland.

Ehemann.

Weib.

Gebähning.

\section{$\S 20$. De los parientes y amigos \\ Von den Bluts-Befreunden}

$\begin{array}{llll}\text { bisagielo } & \text { Uranherr. } & \text { hyo [hijo] bastardo } & \text { Hurenkind. } \\ \text { bisagüela } & \text { Uranfrau. } & \text { tío } & \text { Vetter. } \\ \text { agüelo } & \text { Anherr. } & \text { tia } & \text { Vaass, oder Mamb. } \\ \text { agüela } & \text { Anfrau. } & \text { primos hermanos } & \text { Schwesterkinder. } \\ \text { padre } & \text { Vatter. } & \text { primo } & \text { Vetter. } \\ \text { antecessores } & \text { Voreltern. } & \text { sobrino } & \text { Enckel. } \\ \text { madre } & \text { Mutter. } & \text { sobrina } & \text { Kindstochter. } \\ \text { padrastro } & \text { Stieffiatter. } & \text { padrino } & \text { Göth. } \\ \text { madrastra } & \text { Stieffmutter. } & \text { ahyado [ahijado] } & \text { Göth. } \\ \text { hyo [hijo] } & \text { Sohn. } & \text { huérfano, pupilo } & \text { Pflegkind. } \\ \text { hiya [hija] } & \text { Tochter. } & \text { madrina } & \text { Gottl. } \\ \text { hyastro [hijastro] } & \text { Stieffsohn. } & \text { marido } & \text { Mann. } \\ \text { hyastra [hijastra] } & \text { Stiefftochter. } & \text { muger } & \text { Weib. } \\ \text { nuera } & \text { Schnur. } & \text { hyos [hijos] } & \text { Kinder. } \\ \text { hermano } & \text { Bruder. } & \text { dádiva, dote } & \text { Morgengab. } \\ \text { hermano de parte de patre o madre } & \text { Stieffirnder, oder Stieffschwester. } & \text { armas, } & \text { Wappen. }\end{array}$

$\S 21$. De los nombres mecánicos y otras professiones Von denen Nahmen der Handwercks-Leuthen and anderer Professionen

un mercader
platero
huéspede
joyero
esculpidor de cobre
pintor
impressor
architector [architecto]
cervesero [cervecero]
panadero
camnicero
sastre
çapatero
estañero
carpintero
escultor
albanil [albañil]
texedor

Kauffmann.

Goldschmidt.

Würth.

Inbelier.

Kupffersiecher.

Mahler.

Buchdrucker.

Baumeister.

Breuer.

Beck.

Fleischhacker.

Schneider.

Schuster.

Zingiesser.

Tischer oder Zimmerman.

Bildhauer.

Maurer.

Weber. hierrador

ollero

bañero

enquadernador

serragero [cerragero],

pellejero

molinero

frutero

tintorero

mercader de hierro

ganapán

carretero

un harriero

barbero

cocinero

tabernero, messonero

portero

aldeano, labrador
Schmidt.

Haffner.

Bader.

Buchbinder.

Schlosser.

Kürschner.

Miillner.

Oebster.

Färber.

Eysenkrammer.

Tagwercher.

Fuhrman.

Eseltreiber.

Barbiever.

Koch.

Wirth.

Portner.

Ackersman. 


$\begin{array}{llll}\text { pastor } & \text { Hirt. } & \text { hundidor } & \text { Giesser. } \\ \text { carbonero } & \text { Kohlbrenner. } & \text { lapidario } & \text { Steinschneider. } \\ \text { caçador } & \text { Jäger. } & \text { barquero } & \text { Schiffmann. } \\ \text { falconero } & \text { Falckner. } & \text { costurera } & \text { Naderin. } \\ \text { cirujano } & \text { Wundarzt. } & \text { boticario } & \text { Apotecker. } \\ \text { çurtador } & \text { Gärber. } & \text { sombrerero } & \text { Huterer. } \\ \text { tendero } & \text { Krammer. } & \text { tapicero } & \text { Teppichmacher. } \\ \text { cuchillero } & \text { Messerschmit. } & \text { soguero } & \text { Geisser. } \\ \text { espadero } & \text { Schwerdfeher. } & \text { escopetero } & \text { Büchsenmacher. } \\ \text { sillero } & \text { Sadler. } & \text { vidriero } & \text { Glasser. } \\ \text { calderero } & \text { Kupfferschmid. } & \text { especiero } & \text { Gewïrzkrammer. } \\ \text { perayre, trapero } & \text { Tuchmacher. } & & \end{array}$

$\S 22$. De un jardín con todo lo perteneciente a él Von einem Garten und allem dem was darinnen seyn soll

$\begin{array}{llll}\text { jardinero, hortelano } & \text { Gartner. } & \text { limones } & \text { Lemont. } \\ \text { jardin } & \text { Garten. } & \text { naranja } & \text { Bomeranzen. } \\ \text { ensalada } & \text { Sallat. } & \text { membrillo } & \text { Kitten. } \\ \text { rávano } & \text { Rätich. } & \text { granada } & \text { Granatapf. } \\ \text { cebolla } & \text { Zwiffel. } & \text { fruto } & \text { Frucht. } \\ \text { ajo } & \text { Knobloch. } & \text { raýz } & \text { Wurzel. } \\ \text { verças, colles [coles] } & \text { Kehlkraut. } & \text { razimo de huva } & \text { Weintraub. } \\ \text { repollo } & \text { Häpelkraut. } & \text { huva } & \text { Weinbeer. } \\ \text { perexil } & \text { Petersill. } & \text { viña } & \text { Weingarten. } \\ \text { salvia } & \text { Salve. } & \text { oja } & \text { Laub. } \\ \text { hinojo } & \text { Fenichel. } & \text { campo } & \text { Feld. } \\ \text { ruda } & \text { Rauten. } & \text { sembrar } & \text { Säen. } \\ \text { ortiga } & \text { Brennestl. } & \text { simiente } & \text { Saamen. } \\ \text { dormidera } & \text { Magen-Samen. } & \text { quadaña [guadaña], hoz } & \text { Sichel. } \\ \text { calabaça } & \text { Kirbez. } & \text { prado } & \text { Wisen. } \\ \text { melón } & \text { Melon. } & \text { heno o feno } & \text { Heu. } \\ \text { asencio } & \text { Wermuth. } & \text { yerba } & \text { Kraut oder Grass. } \\ \text { flor } & \text { Blum. } & \text { paja } & \text { Stroh. } \\ \text { rosa } & \text { Rosen. } & \text { seco } & \text { Dürr. } \\ \text { árbol } & \text { Baum. } & \text { hongo } & \text { Pffferling. } \\ \text { mançana } & \text { Apffel. } & \text { romero } & \text { Rossmarin. } \\ \text { pera } & \text { Birn. } & \text { çarça } & \text { Brombeerstaud. } \\ \text { nuez } & \text { Nuss. } & \text { mora de çarça } & \text { Brombeer. } \\ \text { ceresa [cereza] } & \text { Kerschen. } & \text { alcarchofa } & \text { Artitschocken. } \\ \text { guinda } & \text { Weixel. } & \text { nabos } & \text { Rueben. } \\ \text { guindas grandes } & \text { Amarellen. } & \text { ramo } & \text { Zweig. } \\ \text { pèrsico, melacotón [melocotón] } & \text { Pfersen. } & \text { moral } & \text { Maulbeerbaum. } \\ \text { higo } & \text { Feigen. } & \text { mora } & \text { Maulbeer. } \\ \text { avellanas } & \text { Hasselnuss. } & \text { cidrón, cidra } & \text { Zitron. } \\ \text { castaña } & \text { Kesten. } & \text { Euchel. } \\ \text { cirhuelas } & \text { Zwespen. } & \text { cucumer. } \\ \text { oliva } & \text { Oliven. } & \text { Erdbeer. } \\ & \text { frazas [fresas] } & \end{array}$


$\S 23$. De todo género de especierías o especias Von dem Gewürtz und dessen Geschlecht

pimienta

henebro

clavo

canela

açafrán

incienso

almendras

acúcar [açúcar]

higos

anis

granero
grano
trigo
senteno [centeno]
cevada
avena
hava

color

encarnado

colorado

leonado

roxo

azul

verde
Pfeffer.

Imber.

Nägl.

Zimetrind.

Saffran.

Weyrauch.

Mandel.

Zucker.

Feigen.

Aneiss.

passas
alcaparras
flor moscada
goma
reybárbaro
trementina
açúcar candia
dátiles
maná

$\S 24$. De todas suertes de legumbres y granos Von allerlen Getrand und Hülsen-Früchten

Korn-Kasten.

Korn.

Waissen.

Rocken.

Gersten.

Haabern.

Bonnen. myo [mijo]

arroz

chícharas [chicharos], pésoles

carabanças [garbanças]

lentejas

mostaça

almástica
Ziweben.

Cabry.

Muscatblühe.

Gumme.

Rebarbara.

Terpentin.

Zuckergandl.

Dattelkern.

Mana.
Breun oder Hirschen.

Reiss.

Arbes.

Cisern.

Linsen.

Genff.

Mastix.

\section{$\S 25$. De los colores \\ Von denen Farben}

die Farb.

Leibfarb.

Rosenfarb.

Leberfarb.

Roth.

Blau.

Grün.

pardo
blanco
negro
obscuro
amarillo
plateado
descolorido

Grau.

Weiss.

Schwarz.

Dunckel.

Gelb.

Silberfarb.

Bleich.

$\S 26$. De los [sic] más principales fiestas del año Von den vornehmern Fest-Tägen dess Jahrs

Navidad

el Año Nuevo

las fiesta de los tres Reyes

la Candelaria

la [sic] Carnaval

la Quaresma

el dia de Ceniza

la Seana Santa
Weynachten.

das Neue Jahr.

der heiligen drey König Tag.

Liechtmess-Tag.

der Frasching.

die Fasten.

Aschermittwoch.

die Charwochen. el Jueves Santo

el Viemes Santo

la Pascua de Resurrección

la Assención

la Pentecostés

la fiesta de Todos los Santos

la fiesta del Corpus

el Avento
Gründonnerstag.

Charfreytag.

Ostern.

Auffahrts-Tag.

Pfingsten.

Allrheiligen-Tag.

Fronleichnams-Tag.

das Advent. 
los Caniculares

dia de trabajo die Hunds-Täg.
ein Werck-Tag.

dia de fiesta

día de nacimiento ein Feyer-Tag.

Geburts-Tag.

\section{$\S 27$. De diversos géneros de juegos Von denen Spilen}

naypes
dança, bayle
entramés [entremés], gomedia
[comedia]
tablero, damero
juegos de manos
una máscara

Kartenspil.
Danz.
Comedi.
Spillbrett.
Gauckelspil.
ein Larven.

mascarada

Mumerey.

una pelota

ein ballen.

juego de pelota

Ballenspil.

Kegel, Kugel.

birlos, bolos

Kege!.

dados

Würffel.

VOCABULARIO

de algunos verbos más usados y necessarios

Von etlichen nothwendigeren und gebräuchlicheren Verbis

\begin{tabular}{|c|c|c|c|}
\hline \multicolumn{2}{|l|}{ A } & agradar & gefallen. \\
\hline abandonar & verlassen. & aguar & wässern. \\
\hline abborrecer & abschevhaben. & agujerar & durchlöchern. \\
\hline abbreviar & abkïrzen. & ahogarse 0 annegarse & erträncken. \\
\hline ablandar & mildern. & ahorcar & auffhencken. \\
\hline abominar & scheuen. & airarse & sich zörnen. \\
\hline abortar & missgebähren. & alabar & loben. \\
\hline abraçar & umbfahen. & alargar & erlängern. \\
\hline abrasarse & verbrennen. & alegrarse & sich erfreuen. \\
\hline abrir & auffmachen. & aliviar & erringern. \\
\hline absolver & losssprechen. & allanar & ebenen. \\
\hline abstener & enthalten. & almorçar & fruhestucken. \\
\hline acabar & enden. & alojar & beherbergen. \\
\hline acelerar & beschleinigen. & alzar & erheben. \\
\hline acceptar & annehmen. & amar & lieben. \\
\hline acompagnar & gesellschaffleisten. & ampliar 0 enzanchar [ensanchar] & verweitern. \\
\hline acomodar & accomodiren. & angustiar & aengstigen. \\
\hline aconsejar & rathgeben. & anhelar & nachtrachten. \\
\hline acordarse & sich erinnern. & animar & anfrischen. \\
\hline acortar 0 abbreviar & abkürzen. & añadir & zusetzen. \\
\hline acostumbrar & gewohnen. & anteponer & vorsetzen. \\
\hline acusar & anklagen. & anular & zernichten. \\
\hline adelantar & fortgehen. & anunciar & ankünden. \\
\hline adorar & anbetten. & apartarse & sich entfernen. \\
\hline adquerir & erlangen. & aparecer & erscheinen. \\
\hline advertir & in Obacht nehmen. & apetecer & gelüstig seyn. \\
\hline aficionarse & Geneigt sein. & aplacar & stillen. \\
\hline afligir & bestürzen. & apodera[r]se & sich bemächtigen. \\
\hline afrentar & beschänden. & apparejar & zuriisten. \\
\hline agradecer & Danckbahr seyn. & apreciar & schätzen. \\
\hline
\end{tabular}




aprehender
apretar
aprovechar
arar
arder
armarse
arrancar
arrepentir
arrimar
assar
assecurar
assentarse
assentar el campo
assistir
atar
augmentar
avisar
ayunar
azotar

\section{B}

bañar

baratar

barter

bastar

batir

bajar

baylar

besar

bever

blanquear

bolver

bombear

bramar

brillar

brindar

burlar

buscar

C

caçar

caer

cagar

calçarse

calentarse

callar

calumniar

caminar

cansarse

cantar lehren. $\quad$ captar

trucken oder antreiben. carecer

zu mutzmachen. cargar

ackern.

därffen.

sich wafinen.

aussreissen.

bereuen.

anlähnen.

braten.

versichern.

sich setzen.

das Lager schlagen.

beystehen.

binden.

vermehren.

zuwissen thun.

fasten.

beutschen.

baden.

wechseln.

ansskehren.

genug seyn.

zerschlagen.

hinabgehen.

danzen.

kussen.

trüncken.

weissen.

wiederkommen.

bombardiren.

verlangen.

schimeren.

zubringen.

vexiren.

suchen.

jagen.

fallen.

scheissen.

sich anziehen.

sich wärmen.

schweigen.

verleimbden.

gehen.

ermuiden.

singen. casarse

castigar

castrar

cavar

causar

cegar los ojos

celebrar

cenar

ceñir

cerrar

cessar

chocar

circundar

citar

clavar

cobrar

coger

cohabitar

colgar

colocar

colorear

combidar

començar

comer

cometer

compadecerse

comparar

comparecer

compensar

componer

comprar

comprehender

comunicar

concebir

conceder

concertar

concluyr

concordar

concurrit

condenar

conducir

confessar

confiar

confirmar

confortar

conjelar

conocer erwerben.

liebkosen.

Jaden.

heyrathen.

abstraffen.

beschneiden.

haven.

verursachen.

erblinden.

celebriren.

zu Nacht essen.

gïrten.

zuschliessen.

auffhören.

spilen.

umbgehen.

citiren.

naglen.

bekommen.

zwingen.

beywohnen.

hangen.

beysetzen.

färben.

einladen.

anfangen.

essen.

begehen.

mitleydig seyn.

vergleichen.

miterscheinen.

vergelten.

zurichten.

kauffen.

ergreifen.

mittheilen.

empfangen.

zulassen.

ubereinskommen.

beschliessen.

übereinsstimmen.

mitwuircken.

verdammen.

führen.

vekennen.

vertrauen.

bekräffigen.

stärcken.

zusambfriihren.

erkennen. 


\begin{tabular}{|c|c|c|c|}
\hline conseguir & erlangen. & desterrar & das Land verweisen. \\
\hline sonservar & erhalten. & distenguir [distinguir] & unterscheiden. \\
\hline considerar & betrachten. & destribuyr & ausstheilen. \\
\hline consistir & bestehen. & destruyr & verderben. \\
\hline consolar & tröften. & desvanecer & verschwinden. \\
\hline consultar & Rath halten. & detener & auffhalten. \\
\hline consumir & verzehren. & dever & schuldig seyn. \\
\hline contar & erzehlen. & dexar & lassen. \\
\hline contentar & vergnïgen. & dezir & sagen. \\
\hline continuar & fortfahren. & dictar & angeben. \\
\hline contradezir & widersprechen. & diferir & auffschieben. \\
\hline convalecer & genesen. & dilatar & verlängern. \\
\hline convencer & wberwinden. & disminuyr & vermindern. \\
\hline coronar & crönen. & disparar & schiessen. \\
\hline corregir & verbesseren. & disponer & anordnen. \\
\hline correr & lauffen. & disputar & wortwechslen. \\
\hline cortar & abschneiden. & distar & entlegen seyn. \\
\hline cozer & rochen. & disvadir [disuadir] & widerrathen. \\
\hline crecer & wachsen. & divertirse & sich divertiren. \\
\hline creer & glauben. & dividir & theilen. \\
\hline criar & aufferziehen. & divulgar & verfïnden. \\
\hline crucifixar & creuzigen. & doblar & verdoppeln. \\
\hline cubrir & decken. & dominar & herrschen. \\
\hline cuydar & Acht haben. & dormir & schlaffen. \\
\hline & & dudar & zweifflen. \\
\hline $\mathrm{D}$ & & durar & verharren. \\
\hline dañar & schaden. & & \\
\hline dar & geben. & $\mathrm{E}$ & \\
\hline debilitarse & schwächen. & echar & werffen. \\
\hline declarar & erklären. & edificar & auffbauen. \\
\hline declinar & abweichen. & educar & auffziehen. \\
\hline defender & beschiitzen. & elevar & erheben. \\
\hline defraudar & berauben. & eligir [elegir] & erwöhlen. \\
\hline degollar & enwürgen. & embaraçar & daran ligen. \\
\hline deleytarse & sich ergezen. & embiar & schicken. \\
\hline deliberar & wohl überlegen. & embidiar & beneyden. \\
\hline delinear & abzeichnen. & emborracharse & sich berouschen. \\
\hline desagradar & missfallen. & emmendar & verbessern. \\
\hline desahogar & ablassen. & empeçar & anfangen. \\
\hline descansar & aussruhen. & empeñar & verpfenden. \\
\hline descargar & abladen. & emular & eiffern. \\
\hline descubrir & entdecken. & encarcelar & einsperren. \\
\hline dessear & wünschen. & encargar & auffaden. \\
\hline deshazer & zernichten. & encerrar & einsperren. \\
\hline desheredar & enterben. & encontrar & antreffen. \\
\hline desmayarse & ohnmächtig werden. & encubrir & auffdecken. \\
\hline desnudar & entblässen. & endurecer & erharten. \\
\hline despachar & abfertigen. & engañar & betrügen. \\
\hline despirtar [despertar] & auffwecken. & engordarse & feist werden. \\
\hline despreciar & verachten. & enquadernar & einbinden. \\
\hline
\end{tabular}


enriquecer

enseñar

entender

entrar

entregar

entretener

errar

escandalizar

escapar

esconder

escuchar

escusar

espavilar

especular

esperar

espirar

estampar

estar

estender

estimar

estirpar

estudiar

evacuar

evitar

examinar

exceder

exceptar

excluir

executar

exercitarse

exhortar

extimpar

F

fabricar

facilitar

faltar

fatigar

favorecer

fenecer

fiar

fingir

firmar

fregar

freqüentar

fundir

G

ganar

gargantear reich werden.

lehrnen.

verstehen.

hereingehen.

einhändingen.

auff oder unterhalten.

fählen.

aergern.

darvonlauffen, oder ausskommen.

verbergen.

anhören.

enschuldigen.

liechtbuzen.

nachdencken.

hoffen.

entseelen.

drucken.

seyn.

aussbreiten.

schätzen.

ausstilgen.

studiren.

ausslähren.

verhüten.

befragen.

uber die Mass trettien.

aussnehmen.

aussschliessen.

verrichten.

sich üben.

ermahnen.

aussrotten.

bauen.

leicht machen.

abgehen.

bemühen.

giunstigen.

aussgehen.

trauen.

dichten.

befestigen.

abreiben.

besuchen.

giessen.

gewinnen.

gurglen. astar

gemir

g[u]isar

golpear

govemar

gozar

gritar

gruñir

guardar

gustar

$\mathrm{H}$

habitar

hablar

halagar

hallar

haver

hazer

hechar

heredar

herir

hermosear

hilar

hinchar

hontar [honrar]

hospetar [hospedar]

huir

humillarse

hurtar

I

jactarse

ignorar

igualar

illuminar

illustrar

imaginar

imitar

impedir

implora

imprimir

impugnar

imputar

inchar

incitar

inclinar

incluir

incorporar

indicar

indignarse 0 airarse verzehren.

heulen.

sieden.

schlagen.

herrschen.

genüssen.

schreyen.

brumen.

hieten.

kosten.

wohnen.

reden.

schmeichlen.

finden.

haben.

machen.

werffen.

erben.

verwunden.

schön werden.

spinnen.

schwellen.

ehren.

bewirthen.

filegen.

demüthigen.

stehlen.

sich rühmen.

umwissend seyn.

gleichen.

erleuchten.

erweisen.

einbilden.

nachfolgen.

verhindern.

anruffen.

eintrucken.

in Abred seyn.

zumessen.

schwellen.

antreiben.

zuneigen.

einsperren.

einverleiben.

anzeigen.

sich erzürnen. 


\begin{tabular}{|c|c|c|c|}
\hline $\begin{array}{l}\text { infamar } \\
\text { inficionar }\end{array}$ & $\begin{array}{l}\text { schänden. } \\
\text { anstecken. }\end{array}$ & $\begin{array}{l}\text { mandar } \\
\text { manifestar }\end{array}$ & $\begin{array}{l}\text { befehlen. } \\
\text { offenbahren. }\end{array}$ \\
\hline inflamar & entzïnden. & mantener & behaubten. \\
\hline informar & berichten. & marchar & marschiren. \\
\hline inquerir & nachforschen. & matar & tödten. \\
\hline inquietar & beunruhigen. & mear & das Wasser abschlagen. \\
\hline instar & anhalten. & medir & Messen. \\
\hline instituir & anstellen. & mejorar & verbessern. \\
\hline intentar & versuchen. & menospreciar & gering schätzen. \\
\hline interceder & vorsprechen. & mercar & kauffen. \\
\hline interponer & zwischen setzen. & merendar & jausen. \\
\hline interpretar & dolmätschen. & meter & dareinthun. \\
\hline interrogar & fragen. & militar & streiten. \\
\hline interrumpir & zwischen fallen. & minar & trohen. \\
\hline intervenir & zwischenkommen. & minorar & vermindern. \\
\hline inventar & inventiren. & mirar & schauen. \\
\hline investigar & durchsuchen. & mitigar & mildern. \\
\hline inundar & uberschwimmen. & moderar & lindern. \\
\hline inferir & eintragen. & mojar & nassmachen. \\
\hline ir & gehen. & molestar & beunruhigen. \\
\hline ir $[r]$ itar & zornig werden. & montar & auffsteigen. \\
\hline juegar & spillen. & morder & beissen. \\
\hline juntar & zusamb bringen. & morir & sterben. \\
\hline jurar & schwören, schelten. & mostrar & zeigen. \\
\hline \multirow{2}{*}{ juzgar } & urtheilen. & mover & bewegen. \\
\hline & & mudar & endern. \\
\hline $\mathrm{L}$ & & multiplicar & vermehren. \\
\hline ladrar & bellen. & murmurar & murren. \\
\hline lamentar & klagen. & & \\
\hline lastimar & dauren. & $\mathrm{N}$ & \\
\hline lavar & wachen. & nacer & gebähren. \\
\hline leer & lessen. & nadar & schwimmen. \\
\hline levantar & auffstehen. & narrar & erzehlen. \\
\hline ligar & binden. & navegar & schiffen. \\
\hline limitar & mildern. & necessitar & nöthig seyn. \\
\hline limpiar & säubern. & negar & laugnen. \\
\hline llamar & ruffen. & nombrar & nennen. \\
\hline llegar & ankommen. & notar & mercken. \\
\hline llenar & anfïllen. & numerar & zehlen. \\
\hline llevar & tragen. & & \\
\hline llorar & weinen. & 0 & \\
\hline loar & loben. & obedecer & gehorsamen. \\
\hline \multirow{2}{*}{ luchar } & ringen. & obligar & verbinden. \\
\hline & & obrar & bewercken. \\
\hline M & & observar & beobachten. \\
\hline maquinar & ausssinen. & obstar & in Weeg stehen. \\
\hline durar & zeitigen. & obtener & erhalten. \\
\hline maldezir & versuchen, übelreden. & obviar & entgegen kommen. \\
\hline Itratar & mit einem Übel umbgehen. & occurrir & beyfallen. \\
\hline nchar & beflecken. & occultar & verbergen. \\
\hline
\end{tabular}




\begin{tabular}{|c|c|c|c|}
\hline ofender & beleidigen. & plagar & zusamb legen. \\
\hline ofrecer & anerbieten. & pleitear & Strittigkeit haben. \\
\hline ojear & mit Augen blicken. & poder & können. \\
\hline oir & hören. & podrecer & foullen. \\
\hline oler & rüchen. & poner & setzen. \\
\hline olvidar & vergessen. & $\mathrm{po}[\mathrm{r}] \operatorname{tar}$ & tragen. \\
\hline omitir & ausslassen. & posseer & besitzen. \\
\hline oponerse & sich widersetzen. & preceder & vorgehen. \\
\hline oprimir & unterdnicken. & preciar & schätzen. \\
\hline orar & betten. & precipitar & stürzen. \\
\hline ordenar & anordnen. & predezir & vorsagen. \\
\hline orinar & das Wasser lassen. & predicar & predigen. \\
\hline ornan & zieren. & preguntar & fragen. \\
\hline ostentar & zeigen. & $\begin{array}{l}\text { premiar } \\
\text { preparar }\end{array}$ & $\begin{array}{l}\text { beschencken. } \\
\text { zubereiten. }\end{array}$ \\
\hline $\mathrm{P}$ & & presidir & vorsitzen. \\
\hline padecer & leyden. & prestar & leichen. \\
\hline pagar & zahlen. & presumir & ubernehmen. \\
\hline palpar & greiffen. & pretender & anhalten. \\
\hline palpitar & zappeln. & prevalecer & mehr gelten. \\
\hline parar & stillhalten. & prevenir & vorkommen. \\
\hline perecer & scheinen. & presentar & yorstellen. \\
\hline parir & gebähren. & principiar & anfangen. \\
\hline pasmar & entsetzen. & privar & berauben. \\
\hline passear & spazieren gehen. & procurar & zuwegbringen. \\
\hline pedir & begehren. & produzir & vorstellen. \\
\hline pelear & streitten. & prometer & versprechen. \\
\hline pender & hangen. & promulgar & verkïnden. \\
\hline penetrar & durchtringen. & pronunciar & ausssprechen. \\
\hline pensar & gedencken. & propagar & fortpflanzen. \\
\hline percibir & yernehmen. & proponer & vortragen. \\
\hline perder & verliehren. & prosequir [proseguir] & fortfihren. \\
\hline perdonar & verzeyhen. & proteger & beschützen. \\
\hline perecer & verderben. & provocar & heroussruffen. \\
\hline peregrinar & Kirchfart gehen. & purgar & purgiren. \\
\hline perficionar & vollkommen machen. & & \\
\hline permanecer & verbleiben. & Q & \\
\hline permitir & zulassen. & quebrar & brechen. \\
\hline perpetuar & verewigen. & quedar & bleiben. \\
\hline perseguir & verfolgen. & quemar & brennen. \\
\hline perseverar & verharren. & querer & wollen. \\
\hline persistir & verbleiben. & quexarse & sich beklagen. \\
\hline persuadir & bereden. & quitar & Hinweck nehmen. \\
\hline pertenecer & zugehören. & & \\
\hline pesar & missfallen. & $\mathrm{R}$ & \\
\hline pesar en peso & wögen. & raer & aussradiren. \\
\hline peynar & kämpeln. & rascar & katzen. \\
\hline pintar & mahlen. & ratificar & bekräffigen. \\
\hline pantar & pflanzen. & rebentar & zerbersten. \\
\hline plazer & gefallen. & rebolver & durchblätern. \\
\hline
\end{tabular}




\begin{tabular}{|c|c|c|c|}
\hline recatear & ubereinswerden. & sepultar & begraben. \\
\hline rechaçar & zuruckschlagen. & ser & seyn. \\
\hline recibir & empfangen. & serrar & saagen. \\
\hline reclamar & widerruffen. & servir & dienen. \\
\hline recoger & einziehen. & signar & zeichnen. \\
\hline recompensar & erstatten. & silvar & pfeiffen. \\
\hline reconciliarse & sich vereinigen. & sitiar & belägern. \\
\hline recrear & ergözen. & sobrar & ubrig seyn. \\
\hline redimir & erlösen. & socorrer & zuhilff kommen. \\
\hline referir & erzehlen. & soler 0 acostumbrar & pflegen. \\
\hline regalar & beschencken. & soñar & klingen. \\
\hline regir & regiren. & soplar & blasen. \\
\hline reír & lachen. & sospechar & urteln. \\
\hline relampaguear & blitzen. & subir & auffgehen. \\
\hline relaxar & bachsehen. & subsistir & bestehen. \\
\hline remediar & verbessern. & sudar & schwitzen. \\
\hline remittir & nachlassen. & sufrir & ertragen. \\
\hline remunerar & beschencken. & sujetar & unterwerffen. \\
\hline rendit & ergeben. & superar & uberwinden. \\
\hline repartir & ausstheilen. & suplicar & bitten. \\
\hline repedir [repetir] & widerholen. & suplir & erfüllen. \\
\hline reposar & aussruhen. & suspirar & seuffzen. \\
\hline rescatar & erlösen. & sustentar & unterhalten. \\
\hline reservar & vorbehalten. & & \\
\hline respirar & athnem. & $\mathrm{T}$ & \\
\hline resplandecer & glanzen. & temblar & zittern. \\
\hline responder & antworten. & temer & fürchten. \\
\hline restar & uberbleiben. & templar instrumentos & stimmen. \\
\hline restituir & zuruck geben. & tener & haben, oder halten. \\
\hline revelar & offenbahren. & terminar & enden. \\
\hline bevocar [revocar] & zuruck ruffen. & testar & bezeigen. \\
\hline robar & stehlen. & tetar & saugen. \\
\hline rogar & bitten. & texer & weben. \\
\hline romper & brechen. & tirar & siehen. \\
\hline & & tirar & werffen, oder schissen. \\
\hline S & & tocar & anrühren. \\
\hline saber & wissen. & tolerar & erdulten. \\
\hline sacar & heroussthun. & tomar & nehmen. \\
\hline salar & einsalzen. & tostar & rösten. \\
\hline salir & aussgehen. & trabajar & arbeiten. \\
\hline saltar & springen. & traer & bringen. \\
\hline santificar & heiligen. & transferir & auffschieben. \\
\hline satisfazer & genugthun. & tratar & handlen. \\
\hline secar & trucknen. & trillar & tröschen. \\
\hline seguir & folgen. & trocar & tauschen. \\
\hline sellar & versiglen. & tonar & donnern. \\
\hline sembrar & anbanen. & tropeçar & anstossen. \\
\hline señalar & zeichnen. & turbar & verwirren. \\
\hline sentarse & sitzen. & & \\
\hline separar & absöndern. & & \\
\hline
\end{tabular}


$\mathrm{V}$

valer

variar

vaticinar

velar

vencer

vender

venerar

vengarse

ver

vestir violar

gelten.

verändern.

weissagen.

wachen.

uberwinden.

verkauffen.

verehren.

sich rächnen.

sehen.

ankleyden. violentar

visitar

vituperar

vivir

vomitar

untar

usar

Y

yr schänden.

g[e]walt anthun.

heimsuchen.

tadlen.

leben.

speyen.

salben, oder schmieren.

brauchen.

gehen. 